\title{
EXPERIMENTAL STUDY ON PARTIAL REPLACEMENT OF CEMENT WITH EGG SHELL POWDER AND SILICA FUME
}

\author{
N. Parthasarathi ${ }^{1, *}$, M. Prakash ${ }^{1}$, K. S. Satyanarayanan ${ }^{2}$ \\ Department of Civil Engineering, SRM University, Kattankulathur-603203 (Tamilnadu) India \\ *E-mail : nrnpartha@gmail.com
}

\begin{abstract}
During the world, concrete is presence broadly used for the structure of greatest of the buildings, bridges etc. Presently, the complete construction industry is in exploration of an appropriate and operative the unused product that would greatly minimalize the use of cement and eventually decrease the creation cost. Such a substitute material are egg shell powder and silica fume. Greatest of egg shell waste is willing in landfills short of any pre-treatment since it is conventionally unusable and eventually makes thoughtful eco glitches. Therefore, proper alternate is required to manage the wastes in eco-friendly way. The goal of this investigation work is to use the egg shell powder, silica fume as a limited additional of cement. Egg shell powder is replaced by 5\%,10\% and 15\% in addition with the silica fume by $2.5 \%, 5 \%$, and $7.5 \%$ of weight of cement. An experimental research demonstrates the strength features such as split tensile strength, compressive strength, and flexural strength test of egg shell based concrete were investigated. It is found the strength of the concrete rises with the adding of egg shell powder and silica fume and finally the comparison is made for the egg shell and silica fume added strength of concrete.
\end{abstract}

Keywords: Egg shell, Silica fume, Cement, Compressive strength, Split tensile test, Flexural strength test.

(C) RASĀYAN. All rights reserved

\section{INTRODUCTION}

Today India is the third largest egg producer and fourth in broiler production in the world reported by Food and Agriculture Organization (FAO) Statistics Division. India is developing as the world's second major poultry marketplace with a yearly development of additional than $14 \%$, creating 61 million tons or 3.6 percent of global egg manufacture. The yearly growth amount of egg production is 5-8\%. Separately from this, India ranks sixth in broiler production with a yearly output of 2.39 million tons of broiler meat, as per the approximations of the Ministry of Agriculture. The total poultry industry is appreciated at about 350 billion rupees. About 250,000 tons of egg shell left-over is shaped yearly universal by the food processing manufacturing only. In the account, it was projected that 10000-11000 tons of egg shell has to be willing of each year by egg mainframes and makers in India ${ }^{1}$. Most of egg shell waste is willing in landfills without any pretreatment because it is conventionally useless and eventually creates serious eco problems ${ }^{2}$. Therefore, proper alternative is required to achieve the wastes ${ }^{2-4}$. The bioconversion of waste to practical energy is part of the operation of wastes. The actual treatment and operation of bio-waste has been stressed in our society for ecological and economic angles ${ }^{5}$. Removal of egg shell waste are usually not income centers but cost centers ${ }^{6,7}$. Therefore, the smallest cost of discarding is most wanted. Some of the choices left must be observed at very disapprovingly and the greatest cost real method of reprocessing are considered. The research and reported that egg shell consisting $2.2 \mathrm{gms}$ of calcium in the form $\mathrm{CaCO}_{3}$ which is 94 per cent. Remaining masses presented are of large amount of Phosphorous and Magnesium, trace amounts of Sodium, Potassium, Zinc, Manganese, Iron and Copper ${ }^{8}$.

\section{EXPERIMENTAL}

This experimental program involves all the preliminary tests which are carried out in the material and the concrete. These tests help us to know the properties of the material being used for the process of concreting and in the derivation of the mix ratio.

Rasayan J. Chem., 10(2), 442 - 449(2017)

http://dx.doi.org/10.7324/RJC.2017.1021689 


\section{Materials used \\ Cement}

Cement is the important required material for the construction of concrete. Cement is a well-known construction material and has engaged a vital place in construction work. There is a change of cement obtainable in market and each type is used under convinced illness due to its singular properties such as color and arrangement of cement.

Although cement creates only about ten percentage of the volume of the various concrete mix, it is the active portion of the compulsory medium and the only systematically controlled component of concrete. The physical properties of cement, chemical composition of cement are shown in Table- 1 and Table- 2 respectively.

\section{Egg shell}

Table-1: Physical properties of cement

\begin{tabular}{l|l}
\hline Material Property & Test Value \\
\hline Specific Gravity of Cement & 3.14 \\
\hline Fineness of Cement & $3 \%$ \\
\hline Consistency of Cement & $34 \%$ \\
\hline Initial Setting Time of Cement & 35 minutes \\
\hline
\end{tabular}

Table-2: Chemical composition of OPC

The egg shell wastelands in the poultry manufacturing have been highlighted because of its recovery potential. Egg shell waste is available in huge amounts from the food processing, egg breaking, and shading industries. The food indulgence industry is in need of investigation to find another methods for processing and using egg shells waste in an ecological friendly way. There is a need to find a low cost solution. Removal of egg shell waste are usually not income centers but cost centers. Therefore, the least cost of removal is most necessary. Some of the options left should be watched at very critically and the most cost effective method of recycling are considered. The following Table-3 shows the detailed composition of Egg shell.

Table-3: Chemical composition of the egg shell power

\begin{tabular}{c|c}
\hline Oxide contents & Percentage (\%) \\
\hline $\mathrm{CaO}$ & 50.7 \\
\hline $\mathrm{SiO}_{2}$ & 0.09 \\
\hline $\mathrm{Al}_{2} \mathrm{O}_{3}$ & 0.03 \\
\hline $\mathrm{MgO}$ & 0.01 \\
\hline $\mathrm{Fe}_{2} \mathrm{O}_{3}$ & 0.02 \\
\hline $\mathrm{Na}_{2} \mathrm{O}$ & 0.19 \\
\hline $\mathrm{P}_{2} \mathrm{O}_{5}$ & 0.24 \\
\hline $\mathrm{SrO}$ & 0.13 \\
\hline $\mathrm{NiO}$ & 0.001 \\
\hline $\mathrm{SO}_{3}$ & 0.57 \\
\hline $\mathrm{Cl}$ & 0.219 \\
\hline
\end{tabular}


Egg shells procured from local nearby schools regularly and packed in bags. Then the collected egg shells were washed in normal water and then dried in hot sun light for a day to make it dry to make grinding easy and also to avoid the paste formation while grinding. Figure-1 shows the egg shell samples and dried egg shells respectively.

Blackened egg shells were removed separately and the unwanted dust mixed in the sample collections were removed before bringing it to grinding. After collecting, drying and clearing, the samples were placed in a box for manual crushing up to some extent. Then samples were crushed by using some electronic equipment like mixer, grinder, etc.

Approximately each egg shell produces 1 teaspoon of Egg Shell Powder and normally it weighs 5 grams. Like the above, samples were collected from few other schools and dried for easy grinding of the samples. But the egg shells which is grinded in electronic mixer was not as fine as cement. Hence Ball Miller equipment were used to grind the particles finer than the cement.

The grinded egg shells were sieved through the 90 micron sieve size and then packed to use it in the cement replacement.

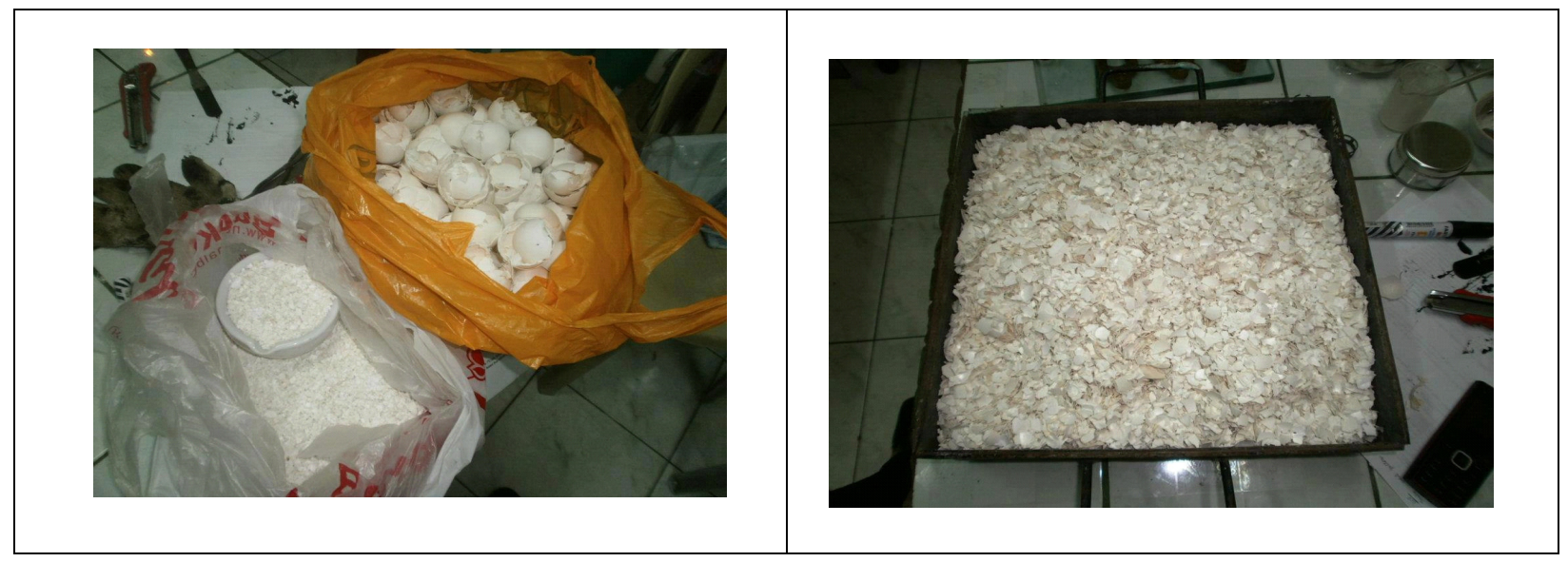

\section{Silica Fume}

Fig.-1: Egg Shell sample before and after crushing

The calculation of silica fume has presented to improve both the and toughness of concrete and compressive strength Also, the presence of this admixture has been shown definite in snowballing the electrical resistivity and the durability of concrete bare to aggressive situations like chloride comprising environments. Pozzolanic materials are usually able to association with the hydrated calcium hydroxide starting the hydrated calcium silicate which is the principal responsible for the benefit of hydrated cement pastes. Also, a rise in the bulk density of concrete fallouts as the mixture voids are occupied with very small admixture elements. The addition of silica fume in concrete leads to decrease in porosity of the evolution zone between matrix and aggregate in the renewed concrete and delivers the microstructure desirable for a robust transition zone. Hence, silica fume is extra with egg shell powder in the cement to recover the strength and durability parameter of the conventional mortar cubes. Silica fume is replaced by $5 \%, 10 \%$ and $15 \%$ by the weight of cement. Physical and Chemical properties of silica fume is shown in Table- 4 and 5 .

Table-4: Chemical composition of silica fume

\begin{tabular}{c|c}
\hline Oxide content & Percentage (\%) \\
\hline $\mathrm{SiO}_{2}$ & 90.21 \\
\hline $\mathrm{CaO}$ & 0.30 \\
\hline $\mathrm{Fe}_{2} \mathrm{O}_{3}$ & 0.15 \\
\hline $\mathrm{Al}_{2} \mathrm{O}_{3}$ & 0.12 \\
\hline $\mathrm{MgO}$ & 0.73 \\
\hline
\end{tabular}




\begin{tabular}{c|c}
\hline $\mathrm{SO}_{3}$ & 0.01 \\
\hline $\mathrm{Na}_{2} \mathrm{O}$ & 0.46 \\
\hline $\mathrm{K}_{2} \mathrm{O}$ & 1.51 \\
\hline
\end{tabular}

Table-5: Physical properties of Silica Fume and Egg shell

\section{Workability}

\begin{tabular}{c|c|c}
\hline S.No. & Materials & Specific Gravity \\
\hline 1 & Silica fume & 2.24 \\
\hline 2 & Egg Shell & 1.01 \\
\hline
\end{tabular}

The workability rises, and thus water content can be reduced by about 3 percentage. The ball behaviour exploit of cementitious particles progresses the workability. Silica fumes and Egg shell petition high water due to advanced fineness.

\section{Mix Combinations}

The following mix combinations as per IS code 10262 - 2009 by trial and error combinations are to be casted and tested by replacing egg shell powder up to $10,20,30 \%$ and silica fume up to $5,10,15 \%$ by weight of cement. The followings Tables- 6 and 7 show the mix combinations of mortar cubes. ${ }^{5}$

Table-6: Mix combination of mortar cubes

\begin{tabular}{l|l|l|l}
\hline Mix combination & Cement (\%) & ESP $(\%)$ & SF $(\%)$ \\
\hline Control & 100 & 0 & 0 \\
\hline E5S0 & 95 & 5 & 0 \\
\hline E10S0 & 90 & 10 & 0 \\
\hline E15S0 & 85 & 15 & 0 \\
\hline E5S2.5 & 92.5 & 5 & 2.5 \\
\hline E10S2.5 & 87.5 & 10 & 2.5 \\
\hline E15S2.5 & 82.5 & 15 & 2.5 \\
\hline E5S5 & 90 & 5 & 5 \\
\hline E10S5 & 85 & 10 & 5 \\
\hline E15S5 & 80 & 15 & 5 \\
\hline E5S7.5 & 87.5 & 5 & 7.5 \\
\hline E10S7.5 & 82.5 & 10 & 7.5 \\
\hline
\end{tabular}

Table-7: Mix proportions

\begin{tabular}{l|l|l|l}
\hline Water & Cement & Fine aggregate & Coarse aggregate \\
\hline 191.58 & 383.16 & 663.765 & 1129.702 \\
\hline 0.5 & 1 & 1.73 & 2.94 \\
\hline
\end{tabular}

\section{RESULTS AND DISCUSSION}

The objectives of all the tests are to find the mechanical properties the concrete (Grade M30) with Egg Shell Powder and Silica fume as the replacement of cement. The strength properties such as compressive strength and split tensile strength test results are presented in the tabular form and also in graphical form for better understanding. The results are analyzed, compared between the various mix proportions.

\section{Compressive Strength}

Compressive strength is by far the maximum important possessions checked for the concrete and even more vital in high performance concrete. Uniaxial compression test is carried out on the specimen $(150 \times 150 \times 150$ $\mathrm{mm}$ cubes) at various days to check the development of compressive strength due to effect of curing. It is clear that cement replaced with egg shell powder up to 15 per cent shows the increase in compressive strength compared with the controlled concrete cubes. Also silica fume added up to 7.5 per cent with the 
weight of cement along with the egg shell powder results increase in compressive strength. Since the addition of Silica fumes doesn't make any broad changes to the Concrete strength, Flexural and Split tensile tests are performed with the plain Egg shell mix only. The comparison of compressive strength for conventional mix and all other eggshell and silica fume concrete mix with different percentage is also done as shown in Figure-3 and 4.

Under uniaxial compression the blows are about parallel to the practical load but some blows form at a position to the applied load. The similar cracks are triggered by a localized tensile stress in a standard to the compressive load and the motivated cracks occur due to collapse caused by the growth of shear planes. It should be noted that the cracks have formed in two planes equivalent to the load and that the specimen fragments into column type trashes.

The results of compressive strength obtained for all types of specimens by conducting compressive test and the results.

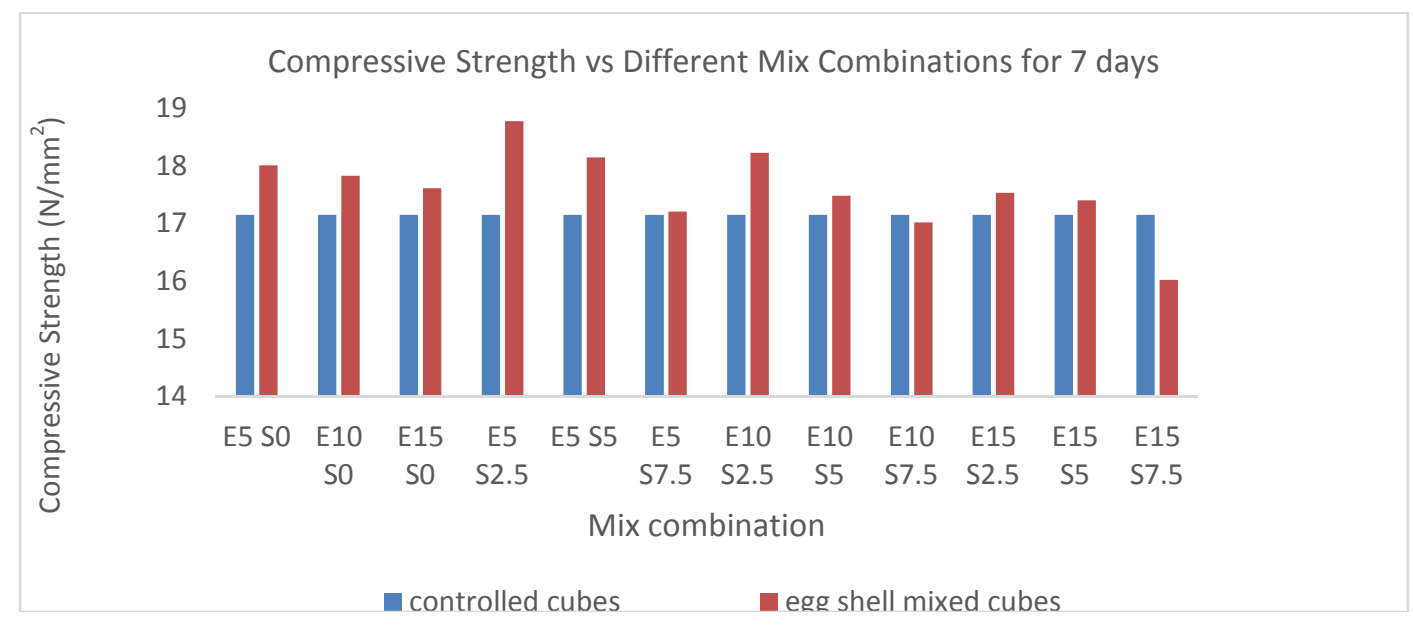

Fig.-3: 7 Days test results for Compressive strength at Different Mix Combination

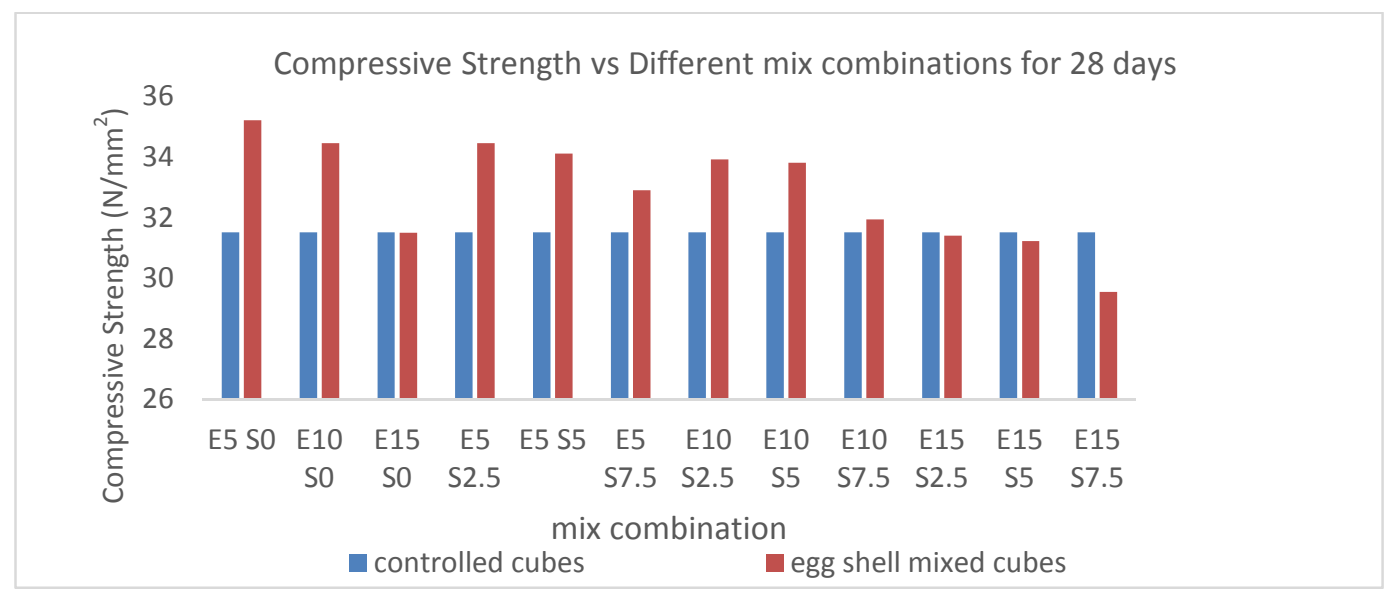

Fig.-4: 28 Days test results for Compressive strength at Different Mix Combination

\section{Split Tensile Strength}

The split tensile strength was tested on $150 \mathrm{~mm}$ diameter $\times 300 \mathrm{~mm}$ length cylinders. The cylindrical specimen was placed with its axis horizontal between platens on the testing machine and the load was increased until failure by splitting in the plane containing the vertical diameter of the specimen. The results of split tensile strength obtained for all types of specimens by conducting split tensile test and the results 
are presented in Table-8. The comparison of strength for conventional mix and all other eggshell powder and silica fume concrete mix with different percentage is also done as shown in Figure-5 and Figure-6.

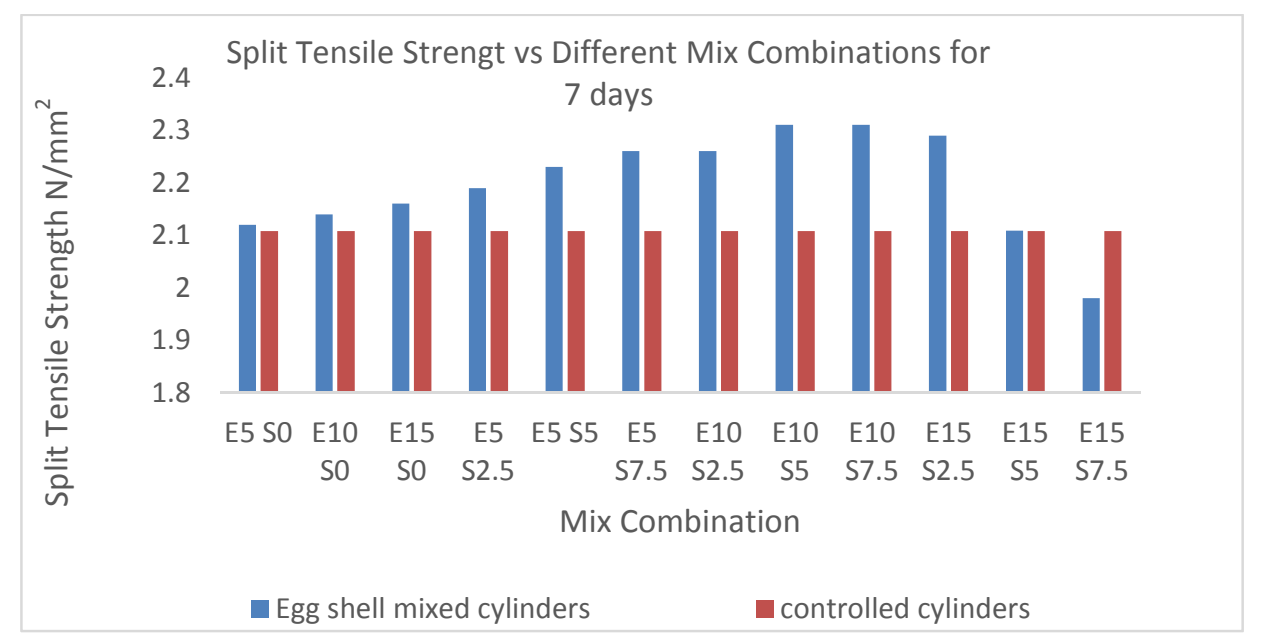

Fig. - 5:7 Days test results for Split Tensile strength at Different Mix Combination

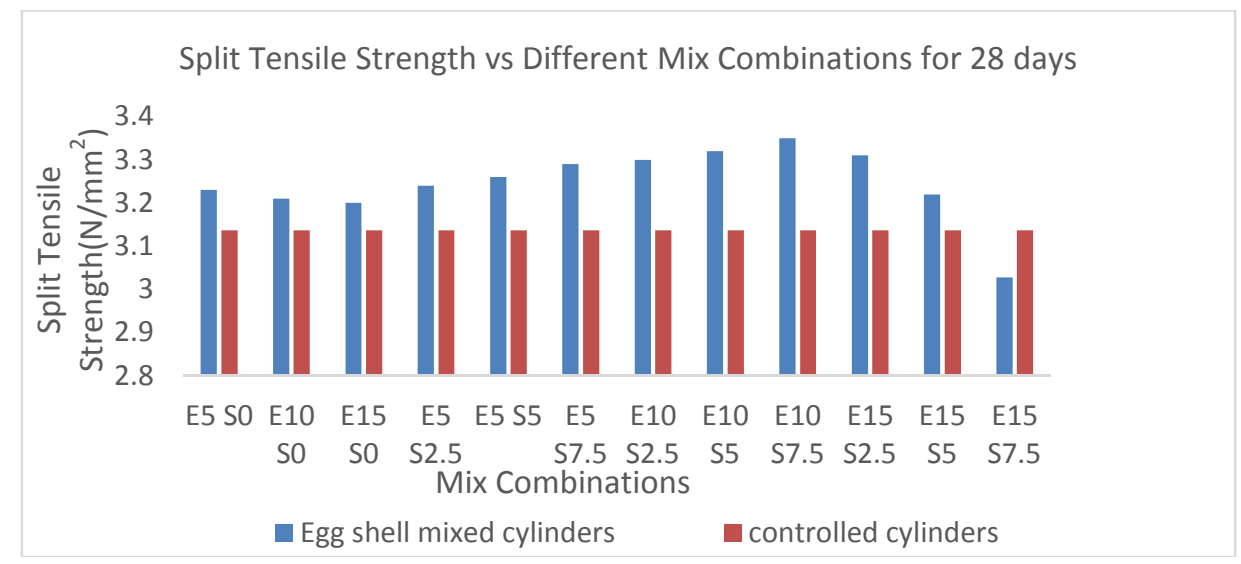

Fig.-6: 28 Days test results for Split Tensile strength at Different Mix Combinations

\section{Flexural Strength Test}

A concrete beam of size is supported on a steel roller manner near each end is loaded through two point loading. Test details are referred from Indian standards. For two-point loading a relentless bending moment is fashioned in the zone between the upper roller bearings. This induces a regular triangular stress circulation along vertical sections from compression above the neutral axis at mid height to tension below the neutral axis. Load and corresponding rebounds were noted up to failure. In each group three beams were confirmed and their average value is reported. The flexural strength was calculated as follows. The flexural strength is calculated as PL/bd2 where P is the total load, L is the distance between the lower supporting rollers and $b$ and $d$ are the breadth and depth of the beam.

The comparison of strength for conventional mix and all other eggshell and silica fume concrete mix with different percentage is also done as shown in Figure-7 and Figure-8.

The cement replacement of egg shell powder up to 15 per cent shows the increase in flexural strength when compare it with the controlled concrete beams. Hence it is concluded that it can be used in practical because it reduces the deflection of the beam. 


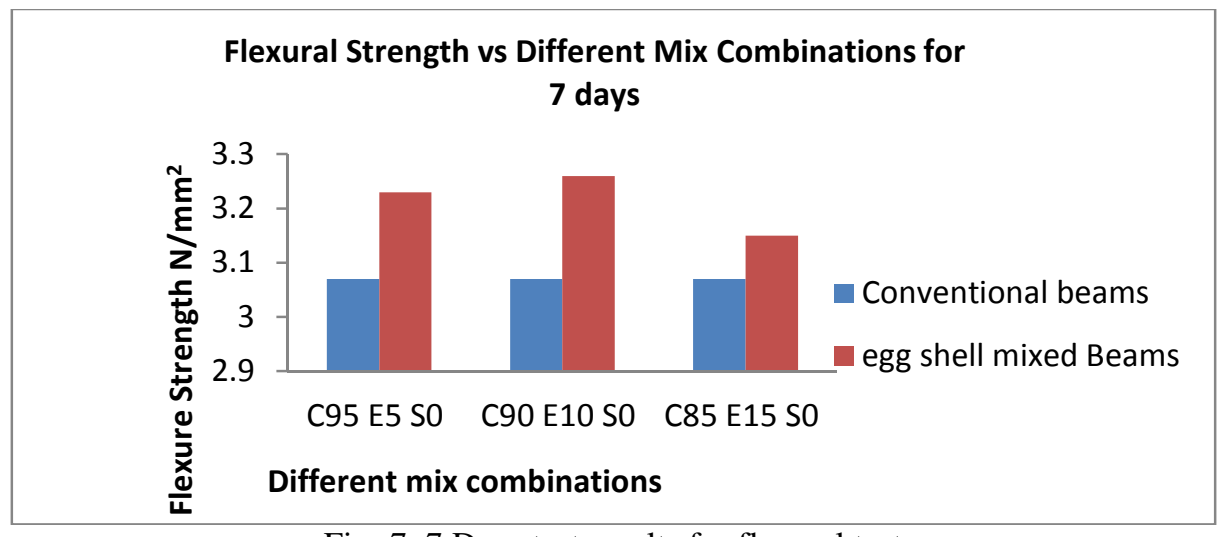

Fig.-7: 7 Days test results for flexural test

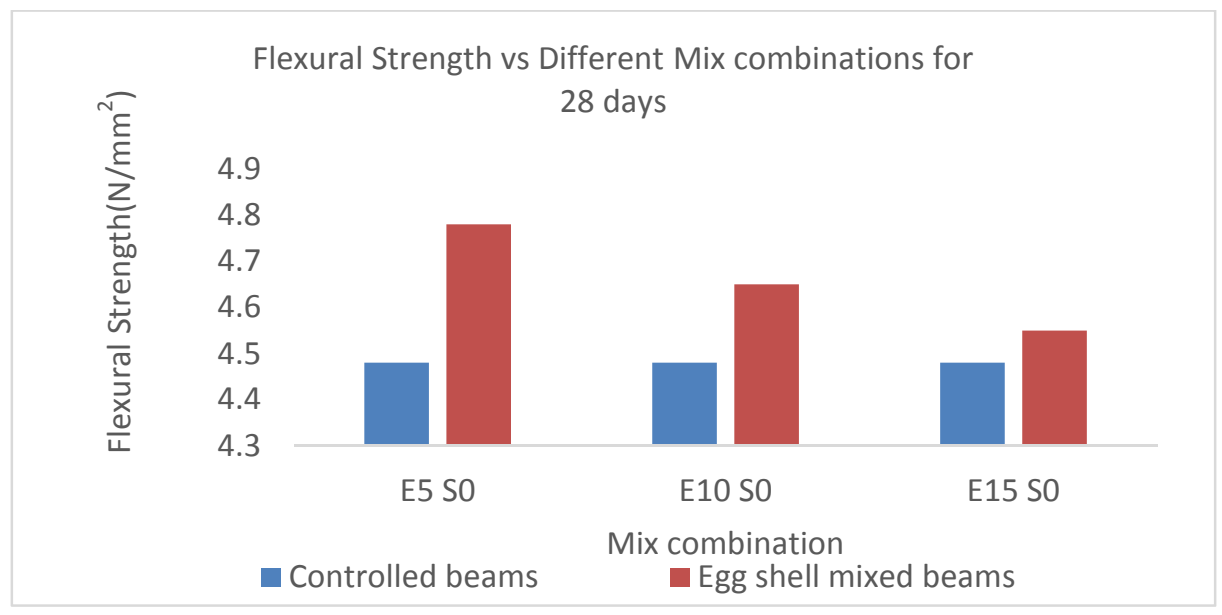

Fig.-8: 28 Days test results for flexural test

CONCLUSION

Extensive experimentation has been carried out to determine utilization of the egg shell powder as cement replacement material by making Concrete cubes and Prisms. . Also to found out the effect of addition of silica fume with the cement. Without the Silica Fumes, the Egg shell powder in various combinations. Based on the results obtained from the experimental work the following conclusions can be drawn

- The compressive strength of the concrete with egg shell powder as cement replacement material increases up to 15 percent without silica fume.

- Addition of silica fume also improves the strength but in inexpensive point of view only the egg shell powder replacement is sufficient enough for getting higher strength.

- The split tensile strength of the egg shell powder concrete decreases with the addition of egg shell powder. This can be increased if the concrete is used with reinforcement.

- The flexural strength of the egg shell concrete increases with the addition of egg shell powder up to 15 percent.

The egg shell powder surrounding the surface of the mix, may increases the Carbonation process and may reduce the Permeability in the long run. Hence a detailed study of Carbonation process in the mix is needed.

\section{REFERENCES}

1. O. Amu, A. B. Fajobi and B. O. Oke, Journal of Agriculture and Biological Science, 1, 80(2005).

2. J. J. Beaudoin and R. F. Feldman, International Journal of Material Science,14, 1681(1979). 
RASĀYAN J. Chem.

Vol. 10 | No. 2 | 442 - 449 | April - June | 2017

3. M. N. Freire and J. N. F. Holanda, Journal of Ceramic, 52, 240(2006).

4. K Chinnaraju, K. Subramanian, and S. R. R. Senthil Kumar, Structural Concrete, Thomas Telford, 1464-4177(2010).

5. IS 10262:2009, Bureau of Indian Standards, New Delhi, India.

6. IS 456:2000 ,Bureau of Indian Standards, New Delhi, India.

7. Kévin Beck, Xavier Brunetaud, Jean-Didier Mertz and Muzahim Al-Mukhtar, Geological Society, London, Special Publications ,331,137(2010).

8. U. N. Okonkwo, I. C. Odiong and E. E. Akpabio, International Journal of Sustainable Construction Engineering \& Technology, 3(1), 18 (2012)

[RJC-1689/2017] 